OPEN ACCESS

Edited by:

Michael T. Milano,

University of Rochester, United States

Reviewed by: Raymond Miralbell,

Geneva University Hospitals (HUG), Switzerland

Maurizio Valeriani,

Sapienza University of Rome, Italy

*Correspondence:

Michael J. Moravan michael.moravan@duke.edu

Specialty section:

This article was submitted to

Radiation Oncology,

a section of the journal

Frontiers in Oncology

Received: 09 April 2019 Accepted: 16 May 2019

Published: 04 June 2019

Citation:

Jacobs $C D$, Palta $M$, Williamson $H$,

Price JG, Czito BG, Salama JK and Moravan MJ (2019) Hypofractionated Image-Guided Radiation Therapy With

Simultaneous-Integrated Boost Technique for Limited Metastases: A Multi-Institutional Analysis. Front. Oncol. 9:469. doi: 10.3389/fonc.2019.00469

\section{Hypofractionated Image-Guided Radiation Therapy With Simultaneous-Integrated Boost Technique for Limited Metastases: A Multi-Institutional Analysis}

\author{
Corbin D. Jacobs ${ }^{1}$, Manisha Palta ${ }^{1,2}$, Hannah Williamson ${ }^{3}$, Jeremy G. Price ${ }^{1}$, \\ Brian G. Czito ${ }^{1,2}$, Joseph K. Salama ${ }^{1,2}$ and Michael J. Moravan ${ }^{1,2 *}$
}

${ }^{1}$ Department of Radiation Oncology, Duke University Medical Center, Durham, NC, United States, ${ }^{2}$ Radiation Oncology Clinical Service, Durham VA Medical Center, Durham, NC, United States, ${ }^{3}$ Department of Biostatistics and Bioinformatics, Duke University Medical Center, Durham, NC, United States

Purpose: To perform a multi-institutional analysis following treatment of limited osseous and/or nodal metastases in patients using a novel hypofractionated image-guided radiotherapy with simultaneous-integrated boost (HIGRT-SIB) technique.

Methods: Consecutive patients treated with HIGRT-SIB for $\leq 5$ active metastases at Duke University Medical Center or Durham Veterans' Affairs Medical Center between 2013 and 2018 were analyzed to determine toxicities and recurrence patterns following treatment. Most patients received 50 Gy to the PTV boost and $30 \mathrm{~Gy}$ to the PTV elect simultaneously in 10 fractions. High-dose treatment volume recurrence (HDTVR) and low-dose treatment volume recurrence (LDTVR) were defined as recurrences within PTV boost and PTV elect, respectively. Marginal recurrence (MR) was defined as recurrence outside PTV elect, but within the adjacent bone or nodal chain. Distant recurrence (DR) was defined as recurrences not meeting HDTVR, LDTVR, or MR criteria. Freedom from pain recurrence (FFPR) was calculated in patients with painful osseous metastases prior to HIGRT-SIB. Outcome rates were estimated at 12 months using the Kaplan-Meier method.

Results: Forty-two patients met inclusion criteria with 59 sites treated with HIGRT-SIB (53\% nodal and 47\% osseous). Median time from diagnosis to first metastasis was 31 months and the median age at HIGRT-SIB was 69 years. The most common primary tumors were prostate (36\%), gastrointestinal (24\%), and lung (24\%). Median follow-up was 11 months. One acute grade $\geq 3$ toxicity (febrile neutropenia) occurred after docetaxel administration immediately following HIGRT-SIB. Four patients developed late grade $\geq 3$ toxicities: two ipsilateral vocal cord paralyzes and two vertebral compression fractures. The overall pain response rate was $94 \%$ and the estimated FFPR at 12 months was $72 \%$. The estimated 12 month rate of HDTVR, LDTVR, MR, and DR was 3.6, 6.2, 7.6 , and $55.8 \%$, respectively. DR preceded MR, HDTVR, or LDTVR in each instance. The estimated 12 month probability of in-field and marginal control was $90.0 \%$. 


\begin{abstract}
Conclusion: Targeting areas at high-risk for occult disease with a lower radiation dose, while simultaneously boosting gross disease with HIGRT in patients with limited osseous and/or nodal metastases, has a high rate of treated metastasis control, a low rate of MR, acceptable toxicity, and high rate of pain palliation. Further investigation with prospective trials is warranted.
\end{abstract}

Keywords: simultaneous-integrated boost, oligometastasis, oligoprogression, radiotherapy, stereotactic, elective, occult, marginal recurrence

\section{INTRODUCTION}

Ever since Hellman and Weichselbaum proposed the existence of the oligometastatic state (1) as a corollary to the spectrum theory of cancer spread (2), there has been increasing interest in treating oligometastatic patients with high-dose preciselytargeted radiation (3). Recent randomized evidence demonstrates progression-free and overall survival improvements with the use of hypofractionated image-guided radiotherapy (HIGRT) to treat limited metastases (4-6). However, the optimal radiotherapy technique used to treat limited metastatic patients remains unknown.

Current radiotherapy techniques to treat oligometastases typically utilize stereotactic body radiotherapy principles including small margins and steep dose gradients $(7,8)$ to minimize potential toxicity of the high dose per treatment. Consistent with this approach is an avoidance of a clinical target volume (CTV) to treat nearby microscopic cancer spread. However, patterns of progression demonstrate that using this technique, recurrences typically occur in nearby structures beyond the treated target volume (9-13).

In an attempt to prevent marginal recurrence (MR) and avoid subjecting patients to another course of treatment, we investigated a simultaneous-integrated boost (SIB) technique when delivering HIGRT. We hypothesized that treating a larger elective volume (including areas at high-risk of harboring occult disease) with a lower dose considered to be well-tolerated by nearby organs at risk, while simultaneously boosting gross disease to a higher dose, would decrease MR with an acceptable toxicity profile.

\section{MATERIALS AND METHODS}

\section{Patient Selection}

Consecutively treated patients with lymph node and/or osseous metastases treated with the HIGRT-SIB technique in the Department of Radiation Oncology at Duke University Medical Center or the Durham Veterans' Affairs Medical Center prior to October 1, 2018 were identified. Patients $>18$ years of age with pathologically confirmed solid tumor malignancy of any primary site with five or fewer active metastatic sites at the time of HIGRTSIB were included in this analysis. The combination of computed tomography (CT) and nuclear medicine imaging (i.e., bone scan and/or positron emission tomography [PET] as indicated by National Comprehensive Cancer Network guidelines) were used to quantify the number of active metastatic sites prior to HIGRTSIB. All prostate cancer patients were staged with a combination of CT scans and technetium- $99 \mathrm{~m}$ bone scans, while all other patients were staged with a combination of CT scans and ${ }^{18} \mathrm{~F}$ fluorodeoxyglucose-PET scans.

We extracted the following information from medical records: age at HIGRT-SIB, gender, primary tumor site, tumor histology, primary tumor treatment, systemic therapy, time to metastatic disease, number of active metastatic sites, largest diameter of metastasis $(\mathrm{cm})$, biomarker level before and after HIGRT-SIB (i.e., prostate specific antigen [PSA], carcinoembryonic antigen [CEA], alpha-fetoprotein [AFP], carbohydrate antigen 19-9 [CA 19-9], and thyroglobulin), presence of painful metastasis prior to HIGRT-SIB, dose per fraction to PTV receiving boost dose $\left(\mathrm{PTV}_{\text {boost }}\right)$, dose per fraction to PTV receiving elective dose $\left(\mathrm{PTV}_{\text {elect }}\right)$, number of fractions, gross tumor volume (GTV, $\left.\mathrm{cm}^{3}\right), \mathrm{PTV}_{\text {boost }}\left(\mathrm{cm}^{3}\right), \mathrm{PTV}_{\text {elect }}\left(\mathrm{cm}^{3}\right)$, and date of death or last follow-Up.

\section{Treatment Technique}

Patients were typically simulated supine with raised arms in a customized immobilization device, with respiratory management and intravenous contrast as indicated with $2-3 \mathrm{~mm}$ CT slices. The GTV was contoured on each axial slice. An elective CTV was contoured encompassing the gross disease and areas at highrisk of occult spread, including the surrounding nodal chain or contiguous bone. Typically, in the case of bony spine metastases, the entire vertebrae was included in the CTV as well as the spinal cord and canal at that level. The CTV was expanded by 5-7 mm in each direction to generate the PTV elect. The GTV was expanded by $0-5 \mathrm{~mm}$ in each direction to generate the PTV $\mathrm{PVost}_{\text {- }}$. Metastases with overlapping $\mathrm{PTV}_{\text {boost }}$ were considered as a single site, unless they involved different organs (e.g., obturator lymph node and pelvic bone).

The most frequently prescribed dose-fractionation was $50 \mathrm{~Gy}$ to the $\mathrm{PTV}_{\text {boost }}$ and $30 \mathrm{~Gy}$ to $\mathrm{PTV}_{\text {elect }}$ over 10 fractions. Organs at risk were contoured and assigned dose constraints compiled from published prospective and retrospective analyses (14-16). The PTV $_{\text {boost }}$ could be selectively under-dosed to meet constraints of dose-limiting organs at risk such as the spinal cord, cauda equina, brachial plexus, and hollow viscera. Treatment was delivered on a linear accelerator with volumetric modulated arc therapy (VMAT) or intensity-modulated radiotherapy (IMRT) with cone beam computed tomography (CBCT) alignment approved by the physician prior to each fraction. Patients were seen once weekly during HIGRT-SIB for assessment of acute toxicity, 4-6 weeks 
after treatment, and then follow-up and imaging performed as clinically indicated.

\section{Outcomes}

The primary outcome was the probability of in-field and marginal control. Events that contributed to this primary outcome include high-dose treatment volume recurrence (HDTVR), low-dose treatment volume recurrence (LDTVR), and MR. HDTVR was defined as clinical and/or radiographic progression or recurrence within the PTV boost. LDTVR was defined as clinical and/or radiographic recurrence within the $\mathrm{PTV}_{\text {elect }}$. MR was defined as clinical or radiographic recurrence outside the $\mathrm{PTV}_{\text {elect }}$ but within the same bone or nearby lymph node chain. Distant recurrence (DR) was defined as clinical or radiographic recurrence at a new site outside the $\mathrm{PTV}_{\text {elect }}$ that did not meet criteria for MR. Three authors (CJ, JS, MM) independently reviewed each clinical and radiographic recurrence, and a consensus categorization was reached in every case.

For metastases from prostate, thyroid, or gastrointestinal primaries with elevated biomarkers prior to treatment, biochemical recurrence (BR) was defined as biomarker elevation above the pre-HIGRT-SIB level. Overall survival (OS) was defined as the time from HIGRT-SIB start to death or last followup date. Disease-free survival (DFS) was defined as the time from HIGRT-SIB start to first recurrence (HDTVR, LDTVR, MR, DR, or BR), death, or last follow-up date, whichever was sooner.

Acute and late toxicities were measured using the Common Terminology Criteria for Adverse Events (CTCAE) version 5.0. Improvement in pain was defined as any decrease in severity on a 10-point scale after HIGRT-SIB. Pain recurrence was defined as equating or exceeding the metastasis pain severity from the pre-HIGRT-SIB level on a 10 -point scale. Freedom from pain recurrence (FFPR) was calculated from the time of HIGRTSIB start to pain recurrence in patients with painful osseous metastases prior to treatment.

\section{Statistical Analysis}

Demographic, tumor, and treatment characteristics were summarized with $\mathrm{N}$ (\%) for categorical variables and median (interquartile range) for continuous variables for all metastases or patients, where applicable. Median length of follow-up was calculated from the start of HIGRT-SIB until death or last contact date for all patients. Crude event rates for each of the previously defined clinical endpoints were calculated out of the applicable populations (i.e., varying denominators). For HDTVR, LDTVR, $\mathrm{MR}$, and probability of in-field and marginal control rates were calculated out of the total number of metastatic sites. Probability of in-field and marginal recurrence was also stratified by whether the metastasis was nodal or osseous and groups were compared with a log-rank test. For DR, OS, and DFS, rates were calculated out of the total number of patients. For BR, the rate was calculated for the total number of patients with pre-HIBRT-SIB elevated biomarkers. For FFPR, the rate was calculated out of the total number of patients with painful osseous sites of disease. Estimates and $95 \%$ confidence intervals (CI) of 1 - and 2 year rates and median time to event for clinical endpoints were estimated using the Kaplan-Meier (K-M) method. Additionally, K-M
TABLE 1 | Demographic, tumor, and treatment characteristics.

\begin{tabular}{|c|c|}
\hline Patient-specific variable $(n=42)$ & $\begin{array}{l}\text { N (\%) or median } \\
\text { (IQR) }\end{array}$ \\
\hline Age at HIGRT-SIB & $69(60-72)$ \\
\hline \multicolumn{2}{|l|}{ Gender } \\
\hline Female & $8(19)$ \\
\hline Male & $34(81)$ \\
\hline \multicolumn{2}{|l|}{ Primary tumor site } \\
\hline Gastrointestinal $^{\star}$ & $10(24)$ \\
\hline Kidney & $1(2)$ \\
\hline Head and neck ${ }^{\circ}$ & $2(5)$ \\
\hline Lung $^{\dagger}$ & $10(24)$ \\
\hline Prostate & $15(36)$ \\
\hline Skin & $3(7)$ \\
\hline Testicle $\ddagger$ & $1(2)$ \\
\hline \multicolumn{2}{|l|}{ Histology } \\
\hline Adenocarcinoma & $27(64)$ \\
\hline Follicular dendritic cell sarcoma & $1(2)$ \\
\hline Hepatocellular carcinoma & $2(5)$ \\
\hline Melanoma & $2(5)$ \\
\hline Merkel cell carcinoma & $1(2)$ \\
\hline Mesothelioma $\ddagger$ & $1(2)$ \\
\hline Papillary thyroid with follicular features & $1(2)$ \\
\hline Renal cell carcinoma & $1(2)$ \\
\hline Small cell carcinoma & $2(5)$ \\
\hline Squamous cell carcinoma & $4(10)$ \\
\hline $\begin{array}{l}\text { Time from diagnosis to first metastasis } \\
\text { (months) }\end{array}$ & $31(5-103)$ \\
\hline \multicolumn{2}{|l|}{$\begin{array}{l}\text { Number of active metastases at time of } \\
\text { HIGRT-SIB }\end{array}$} \\
\hline 1 & $22(52)$ \\
\hline 2 & $13(31)$ \\
\hline 3 & $5(12)$ \\
\hline 4 & $0(0)$ \\
\hline 5 & $2(5)$ \\
\hline \multicolumn{2}{|l|}{$\begin{array}{l}\text { Biomarker level prior to HIGRT-SIB }(n= \\
\text { 23) }\end{array}$} \\
\hline AFP (ng/mL) & $29(5-53)$ \\
\hline CA19-9 (U/mL) & $26^{\star \star}$ \\
\hline CEA (ng/mL) & $8.8(5.9-11.0)$ \\
\hline PSA (ng/mL) & $8.9(2.5-12.0)$ \\
\hline Thyroglobulin ( $\mu \mathrm{g} / \mathrm{L})$ & $216^{\star \star}$ \\
\hline $\begin{array}{l}\text { Treated metastasis-specific variable } \\
(n=59)\end{array}$ & $\begin{array}{l}\text { N (\%) or median } \\
\text { (IQR) }\end{array}$ \\
\hline \multicolumn{2}{|l|}{ HIGRT-SIB target } \\
\hline Lymph node metastasis & $31(53)$ \\
\hline Painful osseous metastasis & $16(27)$ \\
\hline Non-painful osseous metastasis & $12(20)$ \\
\hline \multicolumn{2}{|l|}{ HIGRT-SIB anatomic location } \\
\hline Abdominopelvic & $27(46)$ \\
\hline Spine & $14(24)$ \\
\hline Sternum or rib & $8(14)$ \\
\hline $\begin{array}{l}\text { Supraclavicular fossa, mediastinum, or } \\
\text { axilla }\end{array}$ & $10(17)$ \\
\hline
\end{tabular}

(Continued) 
TABLE 1 | Continued

\begin{tabular}{lc}
\hline $\begin{array}{l}\text { Treated metastasis-specific variable } \\
(\boldsymbol{n}=\mathbf{5 9})\end{array}$ & $\begin{array}{c}\text { N (\%) or median } \\
\text { (IQR) }\end{array}$ \\
\hline $\begin{array}{l}\text { Greatest diameter of largest metastasis } \\
(\mathrm{cm})\end{array}$ & $3.0(2.1-3.7)$ \\
$\mathrm{GTV}\left(\mathrm{cm}^{3}\right)$ & $12.4(4.9-20.9)$ \\
$\operatorname{PTV}_{\text {boost }}\left(\mathrm{cm}^{3}\right)$ & $30.0(15.5-49.7)$ \\
PTV $_{\text {elect }}\left(\mathrm{cm}^{3}\right)$ & $182.7(108.2-315.7)$ \\
Dose to PTV elect & $30(30-30)$ \\
Fractions & $10(10-10)$ \\
HIGRT-SIB duration, days & $13(11-14)$ \\
\hline
\end{tabular}

${ }^{*}$ The distribution among gastrointestinal primary tumors was one anal canal, three colorectal, three esophagus, two liver, and one periampullary.

- One patient had papillary thyroid cancer with follicular features and another had p16negative squamous cell carcinoma of the tonsil.

${ }^{\dagger}$ One patient had medically inoperable oligometastatic extrapulmonary small cell carcinoma and comorbid contraindications to systemic therapy. After HIGRT-SIB, this patient remains disease-free for over 30 months. One patient had follicular dendritic cell sarcoma and received HIGRT-SIB to five sites per multidisciplinary consensus recommendations in lieu of systemic therapy.

¥One patient had oligometastatic testicular mesothelioma.

${ }^{*}$ Single measurement.

AFP, Alpha-fetoprotein; CA 19-9, carbohydrate antigen 19-9; CEA, carcinoembryonic antigen; GTV, gross tumor volume; HIGRT-SIB, hypofractionated image-guided radiotherapy with simultaneous-integrated boost; IQR, interquartile range; PTV, planning target volume; PSA, prostate specific antigen.

TABLE 2 | Acute and late toxicities per treated site of HIGRT-SIB $(n=59)$.

\begin{tabular}{|c|c|c|c|c|}
\hline Toxicity & $\begin{array}{c}\text { Acute grade } \\
1-2 \\
N(\%)\end{array}$ & $\begin{array}{c}\text { Acute grade } \\
\geq 3 \\
N(\%)\end{array}$ & $\begin{array}{c}\text { Late grade } \\
1-2 \\
N(\%)\end{array}$ & $\begin{array}{c}\text { Late grade } \\
\geq 3 \\
N(\%)\end{array}$ \\
\hline Fatigue & $26(55)$ & $0(0)$ & $0(0)$ & $0(0)$ \\
\hline Gastrointestinal & $25(42)$ & $0(0)$ & $6(10)$ & $0(0)$ \\
\hline Genitourinary & $3(5)$ & $0(0)$ & $0(0)$ & $0(0)$ \\
\hline Hematologic* & $2(4)$ & $1(2)^{\dagger}$ & $0(0)$ & $0(0)$ \\
\hline Musculoskeletal & $0(0)$ & $0(0)$ & $2(3)$ & $2(3)^{\ddagger}$ \\
\hline Neurologic & $6(10)$ & $0(0)$ & $0(0)$ & $2(3)^{\circ}$ \\
\hline Respiratory & $2(3)$ & $0(0)$ & $0(0)$ & $0(0)$ \\
\hline Skin & $5(8)$ & $0(0)$ & $0(0)$ & $0(0)$ \\
\hline
\end{tabular}

${ }^{*}$ Rates were reported per course of HIGRT-SIB $(n=47)$.

${ }^{\dagger}$ Febrile neutropenia 5 weeks after completing HIGRT-SIB in a single patient with prostate cancer treated with HIGRT-SIB to two pelvic sites immediately followed by a cycle of docetaxel.

¥Two patients developed ipsilateral vocal cord paralysis.

- One patient required kyphoplasty for compression fracture and one patient required long-term narcotics for vertebral compression fracture limiting activities of daily living.

HIGRT-SIB, hypofractionated image-guided radiotherapy with simultaneousintegrated boost.

estimates of the primary endpoint were calculated for nodal vs. osseous metastases, and K-M estimates of DFS were calculated by number of active metastases at time of HIGRT-SIB. Differences in in-field or marginal recurrence or DFS by metastasis location and number, respectively, were compared between the groups using a log-rank test. Statistical analysis was performed using $\mathrm{R}$ version 3.4.3 (17), with Kaplan-Meier estimates obtained from the survival package (18).

\section{RESULTS}

\section{Baseline Characteristics}

Between July 2013 and October 2018, 42 patients met the inclusion criteria and 59 sites were treated with HIGRTSIB. Demographic, disease, and treatment characteristics are summarized in Table 1. Median time from diagnosis to first metastasis was 31 months, and the median age at HIGRT-SIB was 69 years. The majority of patients had a single (52\%) or two (31\%) active metastatic sites at the time of HIGRT-SIB. The most common primary tumor was prostatic adenocarcinoma (36\%), followed by gastrointestinal (24\%), and lung (24\%).

Among the 59 sites treated with HIGRT-SIB, 53\% were nodal and $47 \%$ were osseous. Nearly one-half $(46 \%)$ of all nodal or osseous metastases were in an abdominopelvic site, and nearly one-quarter $(24 \%)$ were in the cervical, thoracic, or lumbar spine. The median GTV and PTV boost were 12.4 and $30.0 \mathrm{~cm}^{3}$, respectively. The median net PTV enlargement to generate the $\mathrm{PTV}_{\text {elect }}$ was $164 \mathrm{~cm}^{3}$ with respect to $\mathrm{PTV}_{\text {boost. }}$. All but four patients received a prescribed dose of 50 and $30 \mathrm{~Gy}$ in 10 fractions to the $\mathrm{PTV}_{\text {boost }}$ and $\mathrm{PTV}_{\text {elect }}$, respectively. Three patients were selectively underdosed to meet spinal cord or brachial plexus constraints, and one patient received 30 and $20 \mathrm{~Gy}$ in five fractions to the $\mathrm{PTV}_{\text {boost }}$ and $\mathrm{PTV}_{\text {elect }}$, respectively.

\section{Toxicity and Pain Analysis}

Table 2 summarizes the acute and late toxicities per treated site or course of HIGRT-SIB. The most common acute toxicities were grade 1-2 fatigue (55\%) and grade 1-2 gastrointestinal (42\%). An acute pain flare occurred in four osseous sites (14\%) and no nodal sites. Patients requiring a short course of steroids or nonsteroidal anti-inflammatory drugs to facilitate laying comfortably on the treatment table during HIGRT were considered acute grade 1-2 neurologic toxicities (10\%). The incidence of all other acute grade $1-2$ toxicities was $<10 \%$, including dermatitis $(8 \%)$. One acute grade $\geq 3$ toxicity was noted in a patient who received docetaxel immediately following HIGRT-SIB and was subsequently hospitalized for febrile neutropenia. No other acute grade $\geq 3$ toxicities were noted.

Late grade $\geq 3$ toxicity following HIGRT-SIB was noted in four patients. Two of these were vertebral compression fractures; one requiring kyphoplasty and another treated with long-term narcotics for pain that limited the patient's activities of daily living. The two other grade $\geq 3$ toxicities occurred in patients with esophageal cancer treated to the supraclavicular fossa and/or upper mediastinum who developed ipsilateral vocal cord paralysis. One of these patients had hoarseness prior to HIGRTSIB, and underwent multiple esophageal dilations for grade 2 dysphagia. The other patient manifested hoarseness 32 months after completing HIGRT-SIB that did not improve with vocal cord injection. Of note, both of these patients had received prior thoracic chemoradiation therapy for their primary disease and one of the two patients underwent subsequent esophagectomy.

There were 12 patients with painful bony metastases in the study and 11 of them reported pain relief following treatment. The estimated 12 month FFPR was 72\%. In total, there were 16 
TABLE 3 | Crude and estimated rates of clinical endpoints.

\begin{tabular}{|c|c|c|c|c|c|c|c|}
\hline Variable & HDTVR & LDTVR & MR & BR & DR & $\begin{array}{c}\text { Any } \\
\text { recurrence }\end{array}$ & Death \\
\hline Crude events, $n$ (\%) & 2/59 (3\%) & $1 / 59(2 \%)$ & $2 / 59(3 \%)$ & $11 / 23(48 \%)$ & $21 / 42(50 \%)$ & $26 / 42(62 \%)$ & $8 / 42(19 \%)$ \\
\hline Estimated rate at 12 months $(95 \% \mathrm{Cl})$ & $\begin{array}{c}3.6 \% \\
(0.0-10.2 \%)\end{array}$ & $\begin{array}{c}6.2 \% \\
(0.0-17.4 \%)\end{array}$ & $\begin{array}{c}7.6 \% \\
(0.0-18.1 \%)\end{array}$ & $\begin{array}{c}43.4 \% \\
(18.1-60.9 \%)\end{array}$ & $\begin{array}{c}55.8 \% \\
(31.3-71.5 \%)\end{array}$ & $\begin{array}{c}60.1 \% \\
(38.5-74.2 \%)\end{array}$ & $\begin{array}{c}11.9 \% \\
(0.0-22.5 \%)\end{array}$ \\
\hline
\end{tabular}

BR, Biochemical recurrence; $C l$, confidence interval; DR, distant recurrence; HDTVR, high dose treatment volume recurrence; LDTVR, low dose treatment volume recurrence; MR, marginal recurrence.

painful osseous metastatic sites treated, with $15(94 \%)$ noted as having a decrease in severity following treatment.

\section{Patterns of Recurrence}

After a median follow-up of 11 months (interquartile range 624 months), there were five marginal or in-field recurrences (Table 3). The estimated probability of in-field and marginal control at 12 months was $90.0 \%$ (95\% CI $80.9-100.0 \%$, Figure 1A). When stratified by whether a nodal or osseous metastasis was treated with HIGRT-SIB, the estimated probability of in-field and marginal control at 12 months was $86.2 \%(95 \%$ CI 72.5-100.0\%) for nodal metastases and $94.7 \%$ (95\% CI 85.2 $100.0 \%$ ) for osseous metastases ( $p=0.33$, Figure 1B).

After review of individual isodose lines, daily CBCT, and diagnostic surveillance imaging, the crude number of events for HDTVR, LDTVR, MR, and DR were 2, 1, 2, and 21, respectively (Table 3). The estimated rates of HDTVR, LDTVR, MR, and $\mathrm{DR}$ at 12 months were $3.6 \%$ (95\% CI $0.0-10.2 \%$, Figure 2A), 6.2\% (95\% CI 0.0-17.4\%, Figure 2B), 7.6\% (95\% CI 0.0-18.1\%, Figure 2C), and $55.8 \%$ (95\% CI 31.3-71.5\%), respectively. The median time to DR was 11 months, and DR preceded HDTVR, LDTVR, or MR in each instance.

Further exploring MR, one occurred in a patient with lower extremity melanoma initially treated with wide local excision and inguinal nodal dissection who later received HIGRTSIB for ipsilateral external and common iliac lymph node oligometastases. A biopsy-proven recurrence developed in the surgically dissected inguinal region, which was not included in the PTV elect.

Additionally, a lung cancer patient developed both MR and LDTVR following two separate courses of HIGRT-SIB. This patient initially received $60 \mathrm{~Gy}$ to the primary lung tumor and mediastinal lymph nodes with concurrent carboplatin and paclitaxel. The first course of HIGRT-SIB targeted an isolated left upper mediastinal nodal recurrence while attempting to avoid overlap with the initial fields. As depicted in Figure 3, the MR occurred just outside of the $\mathrm{PTV}_{\text {elect }}$, right between the junctions of the radiotherapy fields. The second HIGRT-SIB course treated the right supraclavicular fossa, where a LDTVR likely occurred due to an insufficiently treated subcentimeter oligometastasis that was visible on $\mathrm{CT}$, but not avid on pre-treatment positron emission tomography (PET).

Both HDTVRs occurred in patients with prostate cancer. One patient with castrate-resistance developed widespread osseous metastases on the initial surveillance scan and shortly thereafter demonstrated disease progression within the $\mathrm{PTV}_{\text {boost }} 6$ months after HIGRT-SIB. The second HDTVR occurred 25 months following HIGRT-SIB in one of five treated para-aortic lymph nodes in the setting of chronic immunosuppression and a new primary bladder malignancy.

Of the 23 patients with biochemically-detectable malignancies, 11 met our definition of BR. The median time to BR was 18 months. Among those with BR, the elevated laboratory value preceded any clinical or radiographic recurrence in $73 \%$ of patients.

\section{Survival Analysis}

Eight deaths occurred during the follow-up period (Table 3 ). The median OS was 36.6 months and the estimated 12 month OS was $88.1 \%$ (95\% CI 77.5-100.0\%). Any recurrence occurred in 26 (62\%) patients during the follow-up period. The median DFS was 8.3 months and the estimated 12 month DFS was $38.8 \%(95 \%$ CI $25.1-60.1 \%)$. When stratified by number of active metastatic sites, the median DFS for patients with $1,2,3$, and 5 active metastatic sites prior to HIGRT-SIB was $11.3,7.7,3.7$, and 5.4 months, respectively.

\section{DISCUSSION}

Despite increasing enthusiasm for and growing evidence supporting the treatment of limited or "oligo" metastases with radiation, the optimal radiotherapy technique is unknown. Most of the evidence supporting the use of radiation for limited metastases has been accomplished using small fields directed at gross disease with a minimal margin to decrease the likelihood for toxicity. However, as progression near treated tumors occurs at a significant rate, we sought to decrease the likelihood of such by including an elective, lower-dose volume including adjacent areas at high-risk of harboring occult disease. With this technique, we found high treated tumor control rates, consistent with prior reports using $\operatorname{HIGRT}(11,13,19-37)$. Additionally, we found that the HIGRT-SIB technique altered previously reported patterns of progression, as we saw few in-field or marginal recurrences ( $10 \%$ combined at 12 months). Furthermore, treatment was welltolerated with low rates of acute and late grade $\geq 3$ toxicity, and pain responses following HIGRT-SIB were higher than historical rates observed following standard, palliative radiation doses.

The high rate of treated tumor control ( $96 \%$ at 12 months) seen in our patients treated with this HIGRT-SIB technique was promising. Our results are comparable with reported 12 month local control rates in other studies of HIGRT in oligometastastic patients with spinal $(>80 \%)(20,28,33,36,38,39)$, non-spine 


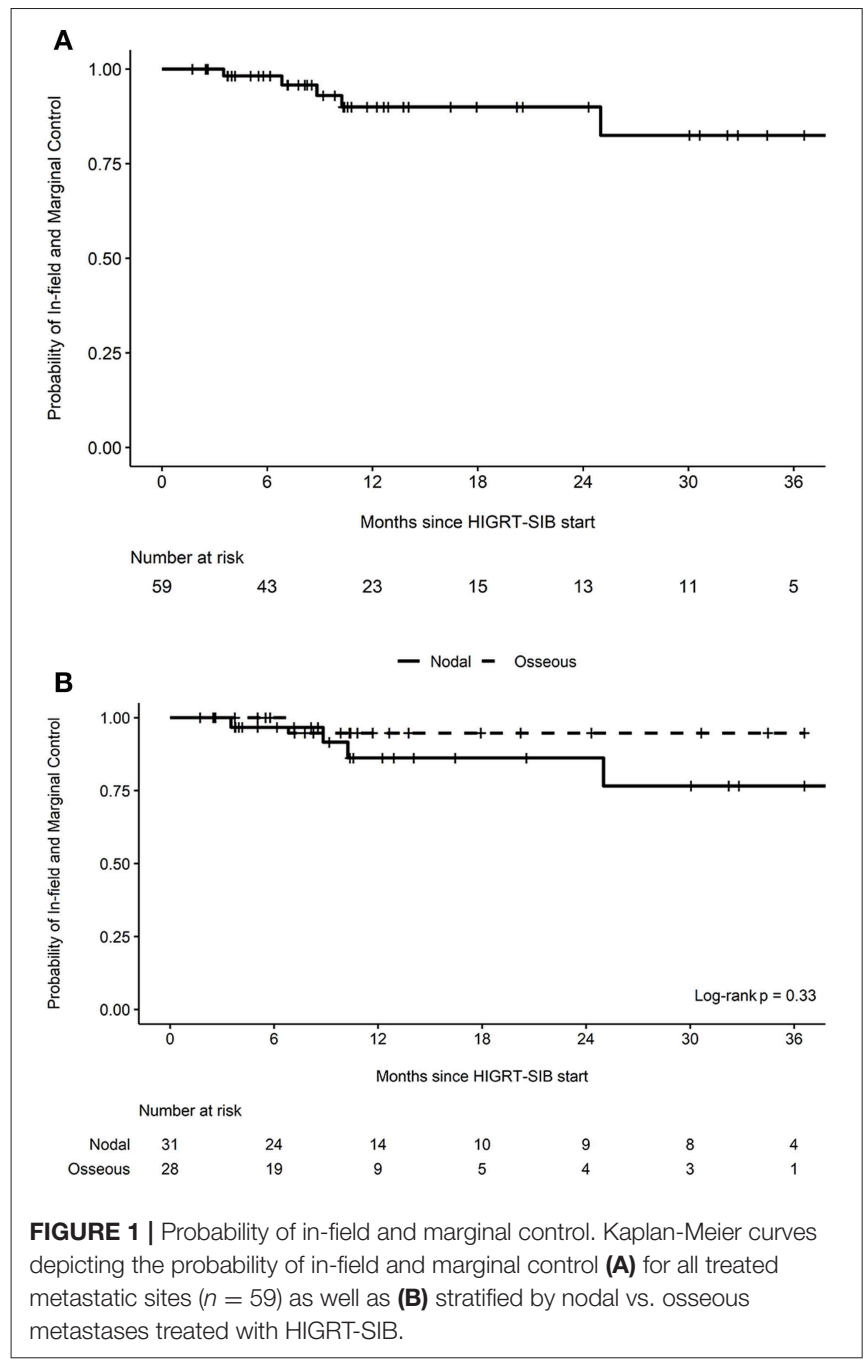

bony $(>91 \%)(19,22,25,26,34)$, and lymph node metastases (>77\%) (11, 13, 21, 23, 24, 29-32, 35, 37), treated to visible tumor only. Additionally, it appears that the inclusion of a low dose $\mathrm{PTV}_{\text {elect }}$ may have reduced nearby progression. Prior studies describing patterns of progression following HIGRT to nodal metastases report $26-55 \%$ recurrence rates in adjacent lymph nodes $(11,13,25)$. For patients with spinal metastases treated with HIGRT, prior studies have described the patterns of progression occurring primarily in the epidural space and/or in adjacent bony elements that have either not been included in the treatment volumes or purposely underdosed in order to meet spinal cord constraints $(9,33,38,39)$. Of the limited studies specifically investigating MR in radiation treated spinal metastases, one reported a crude MR rate of $12.5 \%$ and a cumulative incidence at 12 months of 9.5\% (10). We noted only two MRs and a single LDTVR, corresponding to a combined estimated rate of $5 \%$ at 12 months. Comparison of these rates with prior studies investigating the use of HIGRT for patients with non-spine bony metastases is difficult, as the rates and patterns of progression immediately outside of the treated field

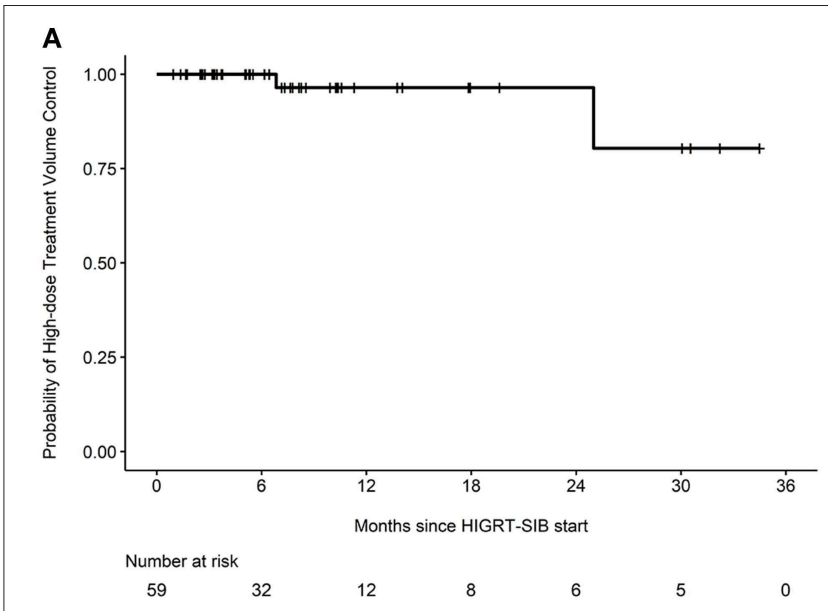

B
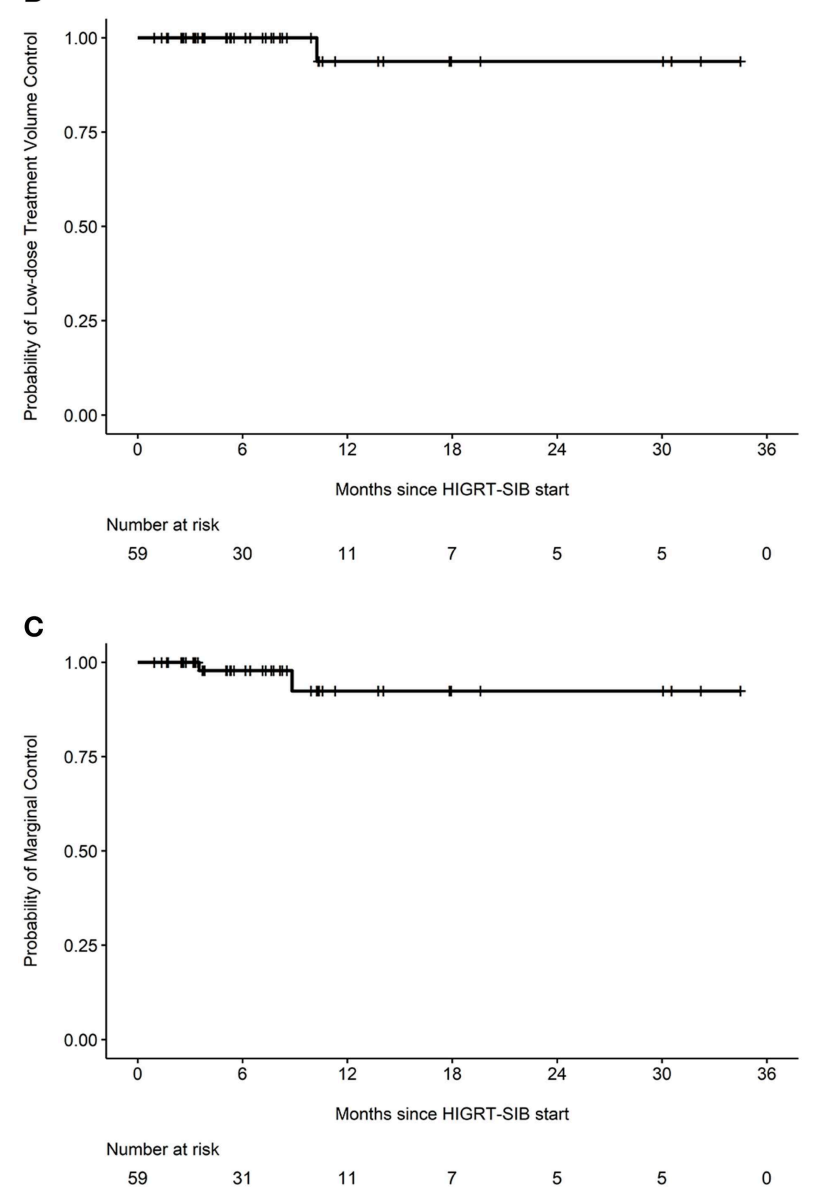

FIGURE 2 | Specific probabilities of in-field and marginal control. Kaplan-Meier curves depicting the probabilities of (A) high-dose treatment volume control, (B) low-dose treatment volume control, or (C) marginal control among all treated metastatic sites $(n=59)$.

are not commonly reported in the existing, limited literature for these patients.

This HIGRT-SIB technique was well-tolerated, as both acute and late grade $\geq 3$ toxicity rates were low $(\leq 10 \%)$. Importantly, 


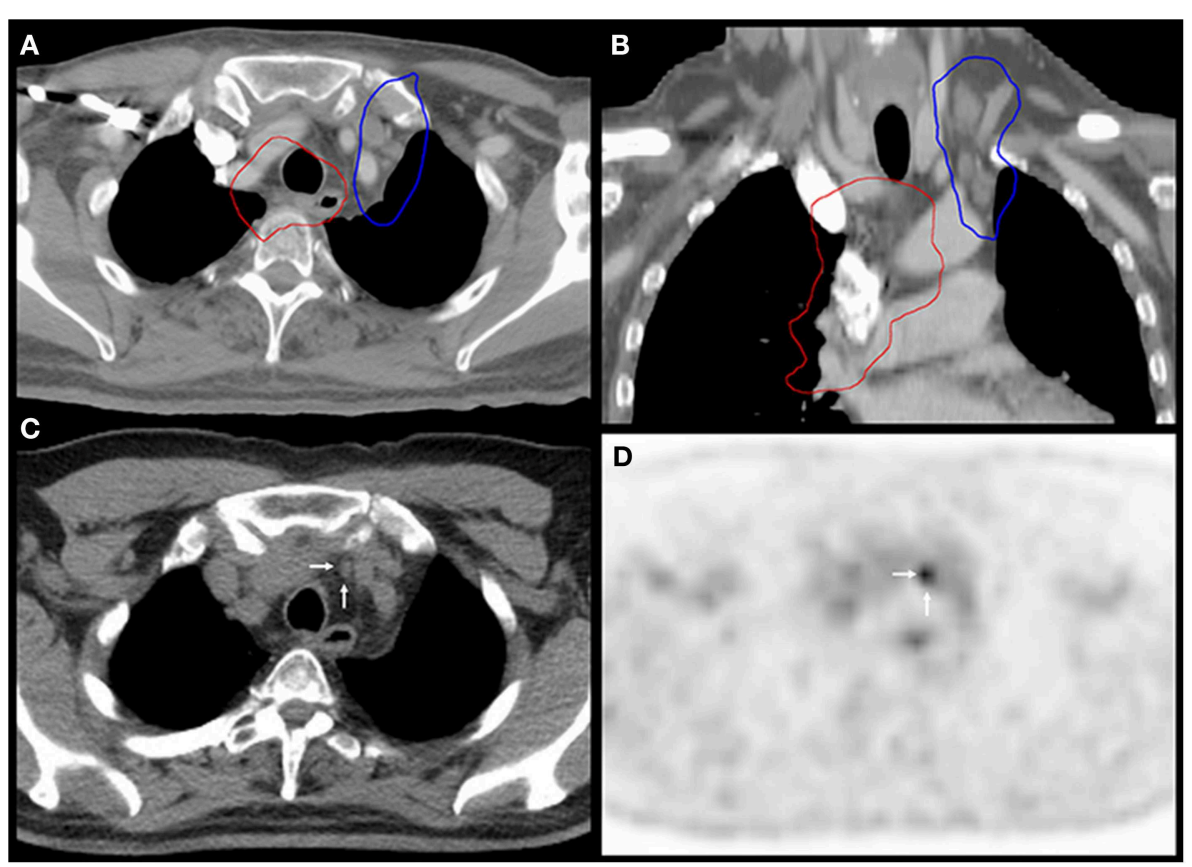

FIGURE 3 | Marginal recurrence between the junctions of radiation fields. Images (A,B) show the 60 Gy isodose lines (red) from the first course of chemoradiation and the 30 Gy isodose lines (blue) from the PTV elect of HIGRT-SIB on fused axial and coronal planning CT images. Images (C,D) correspond to the axial slices of the surveillance PET-CT scan that identified the marginal recurrence (white arrows) in an undertreated lymph node between the junctions of the radiation fields.

we did not observe any bowel obstruction, bowel perforation, gastrointestinal hemorrhage, myelopathy, or death due to HIGRT treatment. Comparison of our observed toxicity rate is difficult due to the heterogeneity of treatment sites included in this analysis. However, our results compare favorably with existing reports, including a recently reported prospective randomized trial of standard of care (SOC) treatment with HIGRT vs. SOC alone in patients with 1-5 metastatic sites that found $29 \%$ experienced acute grade $\geq 2$ toxicity with three treatment-related grade 5 events (6). Another recent randomized trial of HIGRT vs. maintenance chemotherapy in oligometastatic NSCLC patients reported a $20 \%$ grade three treatment-related toxicity rate in the radiation arm (4).

We found that HIGRT-SIB resulted in a high subjective pain response $(>90 \%)$ that was also durable, with $72 \%$ of patients reporting continued pain improvement at 12 months. The pain response rate seen in our study was higher than the rate of $66 \%$ reported for all patients treated on the multi-fraction palliative radiotherapy arm of RTOG 97-14 (40) as well as the rate of $62 \%$ in patients with spine metastases in that trial (41). Our results also compare favorably to reported pain response rates following stereotactic body radiotherapy (SBRT) for spinal metastases (4198\%) $(38,42-44)$ and non-spine bony metastases receiving SBRT $(77-88 \%)(34,45)$.

While others have used a SIB technique to treat limited metastases, our technique is novel in several ways. First, patients in this study were most commonly received 10 fractions, delivering an established oligometastatic treatment dose of $50 \mathrm{~Gy}$ along with an elective dose of $30 \mathrm{~Gy}$, the latter of which is commonly utilized to treat metastatic disease in multiple anatomic sites. Additionally, for osseous spinal metastases we included the entire involved vertebrae, including the posterior elements and spinal canal, in the PTV elect. For non-spine osseous metastases a generous elective volume could be included and for patients with limited lymph node metastases, we targeted occult spread throughout the contiguous lymph node chain and not just the immediate vicinity around the involved node. We were able to treat large volume oligometastases with this technique. Finally, we were able to deliver treatments using commonly available CBCT image-guidance and without more advanced spine SBRT techniques, indicating that many centers may be able to adopt our HIGRT-SIB technique as a tool to treat oligometastatic, oligorecurrent, or oligoprogressive patients in their clinic.

Prior reports of a SIB technique for spinal metastases have utilized a CTV that included the vertebral body and selected, but not all, posterior elements in order to meet spinal cord constraints delivering one fraction of $21-24 \mathrm{~Gy}$ to the GTV and $18 \mathrm{~Gy}$ electively, or alternatively three fractions delivering $30 \mathrm{~Gy}$ to the GTV and $24 \mathrm{~Gy}$ electively (20). For lymph node metastases, HIGRT with a SIB technique utilizing 1-5 fractions with a much smaller low-dose CTV as a 5-mm expansion from gross disease with anatomic modifications has been used (46). Recently, a spinal simultaneous integrated boost (SSIB) technique for patients with spinal metastases considered to be "radiation-resistant" and unsuitable for treatment with standard spine SBRT approaches has been described (47). The study involved 12 patients with 15 treated sites extending between 3 and 5 vertebral body levels that were treated using a 10 -fraction 
SSIB technique. Gross disease was prescribed 40 Gy whereas a CTV including the involved vertebral bodies, at-risk paraspinal space, and spinal canal was prescribed $30 \mathrm{~Gy}$. The 1 year local control rate was $93 \%$, which was similar to our analysis. While only $78 \%$ of patients in this study reported any improvement in metastasis-related pain, $94 \%$ of the treated sites in our analysis resulted in any improvement in pain, potentially reflecting a dose-response relationship. Although the HIGRT-SIB technique and SSIB techniques have many similarities, there are several distinct differences. First, we used a higher dose per fraction to treat our GTV, which may have accounted for the improved pain response. Second, our CTV only included para-spinal areas if there was evidence of extraosseous extension on diagnostic imaging. Lastly, the SSIB technique was specifically utilized in patients with spinal metastases unfit for standard HIGRT, while this study described HIGRT-SIB use for patients with non-spine bony and lymph node metastases.

There are several limitations to our retrospective analysis. First, it is subject to effects from unidentified, potentially confounding variables in this very heterogeneous population. Second, the number of patients is small and the duration of follow-up is short, and therefore may not adequately capture all late toxicities and recurrences. Finally, a major limitation is the lack of a control arm (e.g., HIGRT without SIB and an elective treatment volume) to compare the rates of marginal and treated site recurrence with the experimental HIGRT-SIB technique; however, efforts are currently underway to identify patients treated with standard HIGRT at our centers and further analyses will be forthcoming.

In conclusion, targeting areas at high-risk of occult disease by treating a larger elective volume while simultaneously boosting gross disease with HIGRT in patients with limited osseous and/or nodal metastases has acceptable rates of acute and late toxicity with low rates of marginal or in-field recurrence. HIGRT-SIB showed a high rate of overall pain response that was durable. Further investigation with a prospective trial is warranted to determine if HIGRT-SIB with a PTV elect has

\section{REFERENCES}

1. Hellman S, Weichselbaum RR. Oligometastases. J Clin Oncol. (1995) 13:810. doi: 10.1200/JCO.1995.13.1.8

2. Hellman S. Karnofsky memorial lecture. Natural history of small breast cancers. J Clin Oncol. (1994) 12:2229-34. doi: 10.1200/JCO.1994.12.10.2229

3. Lewis SL, Porceddu S, Nakamura N, Palma DA, Lo SS, Hoskin P, et al. Definitive stereotactic body radiotherapy (SBRT) for extracranial oligometastases: an international survey of $>1000$ radiation oncologists. Am J Clin Oncol. (2017) 40:418-22. doi: 10.1097/COC.000000000 0000169

4. Gomez DR, Blumenschein GR Jr., Lee JJ, Hernandez M, Ye R, Camidge $\mathrm{DR}$, et al. Local consolidative therapy versus maintenance therapy or observation for patients with oligometastatic non-small-cell lung cancer without progression after first-line systemic therapy: a multicentre, randomised, controlled, phase 2 study. Lancet Oncol. (2016) 17:167282. doi: 10.1016/S1470-2045(16)30532-0

5. Iyengar P, Wardak Z, Gerber DE, Tumati V, Ahn C, Hughes RS, et al. Consolidative radiotherapy for limited metastatic non-small-cell similar rates of local control, decreases MR, improves DFS, lengthens systemic therapy-free intervals or delays switching systemic therapies, and/or results in a similar or better toxicity profile compared to standard HIGRT. Importantly, prospective trials are indicated to determine if the described HIGRT-SIB technique increases the overall palliative pain response rate and/or provides more durable pain relief in patients with osseous metastases compared to traditional palliative external beam radiotherapy.

\section{DATA AVAILABILITY}

The datasets generated for this study are available on request to the corresponding author.

\section{ETHICS STATEMENT}

The retrospective research was completed under a protocol approved by the Duke University Medical Center Institutional Review Board (Pro00101071) and a protocol approved by the Durham VA Health Care System Institutional Review Board (MIRB \#1740). Research was conducted under waivers of consent, HIPAA authorization, and decedent notification at both institutions.

\section{AUTHOR CONTRIBUTIONS}

CJ, JS, and MM contributed conception and design of the study and organized the database. CJ and HW performed the statistical analysis. CJ wrote the first draft of the manuscript. MM, JS, HW, BC, JP, and MP wrote sections of the manuscript. All authors contributed to manuscript revision, read, and approved the submitted version.

\section{ACKNOWLEDGMENTS}

The authors would like to acknowledge and thank the Durham VA Medical Center.

lung cancer: a phase 2 randomized clinical trial. JAMA Oncol. (2018) 4:e173501. doi: 10.1001/jamaoncol.2017.3501

6. Palma DA, Olson R, Harrow S, Gaede S, Louie AV, Haasbeek $\mathrm{C}$, et al. Stereotactic ablative radiotherapy versus standard of care palliative treatment in patients with oligometastatic cancers (SABR-COMET): a randomised, phase 2, open-label trial. Lancet. (2019) 393:2051-8. doi: 10.1016/S0140-6736(18)3 2487-5

7. Al-Hallaq HA, Chmura S, Salama JK, Winter KA, Robinson CG, Pisansky TM, et al. Rationale of technical requirements for NRG-BR001: the first NCIsponsored trial of SBRT for the treatment of multiple metastases. Pract Radiat Oncol. (2016) 6:e291-e8. doi: 10.1016/j.prro.2016.05.004

8. Salama JK, Milano MT. Radical irradiation of extracranial oligometastases. J Clin Oncol. (2014) 32:2902-12. doi: 10.1200/JCO.2014. 55.9567

9. Chang EL, Shiu AS, Mendel E, Mathews LA, Mahajan A, Allen PK, et al. Phase I/II study of stereotactic body radiotherapy for spinal metastasis and its pattern of failure. J Neurosurg Spine. (2007) 7:15160. doi: 10.3171/SPI-07/08/151 
10. Koyfman SA, Djemil T, Burdick MJ, Woody N, Balagamwala EH, Reddy CA, et al. Marginal recurrence requiring salvage radiotherapy after stereotactic body radiotherapy for spinal metastases. Int J Radiat Oncol Biol Phys. (2012) 83:297-302. doi: 10.1016/j.ijrobp.2011.05.067

11. Hasselle MD, Salama JK, Tye KE, Golden DW, Liauw SL, Weichselbaum RR, et al. Patterns of progression following hypofractionated image-guided radiotherapy (HIGRT) to abdominal lymph nodes in oligometastatic (OM) patients. Int J Radiat Oncol Biol Phys. (2011) 81:S654. doi: 10.1016/j.ijrobp.2011.06.1924

12. Jereczek-Fossa BA, Ronchi S, Orecchia R. Is stereotactic body radiotherapy (SBRT) in lymph node oligometastatic patients feasible and effective? Rep Pract Oncol Radiother. (2015) 20:472-83. doi: 10.1016/j.rpor.2014. 10.004

13. Ost P, Jereczek-Fossa BA, Van As N, Zilli T, Tree A, Henderson D, et al. Pattern of progression after stereotactic body radiotherapy for oligometastatic prostate cancer nodal recurrences. Clin Oncol. (2016) 28:e115-20. doi: 10.1016/j.clon.2016.04.040

14. Milano MT, Katz AW, Schell MC, Philip A, Okunieff P. Descriptive analysis of oligometastatic lesions treated with curative-intent stereotactic body radiotherapy. Int J Radiat Oncol Biol Phys. (2008) 72:151622. doi: $10.1016 /$ j.ijrobp.2008.03.044

15. Li Q, Swanick CW, Allen PK, Gomez DR, Welsh JW, Liao Z, et al. Stereotactic ablative radiotherapy (SABR) using $70 \mathrm{~Gy}$ in 10 fractions for non-small cell lung cancer: exploration of clinical indications. Radiother Oncol. (2014) 112:256-61. doi: 10.1016/j.radonc.2014.07.010

16. Chance WW, Nguyen QN, Mehran R, Welsh JW, Gomez DR, Balter P, et al. Stereotactic ablative radiotherapy for adrenal gland metastases: factors influencing outcomes, patterns of failure, and dosimetric thresholds for toxicity. Pract Radiat Oncol. (2017) 7:e195-203. doi: 10.1016/j.prro.2016.09.005

17. Team RC. A Language and Environment for Statistical Computing. Vienna (2014).

18. Therneau T. A Package for Survival Analysis in S (2015). Available online at: https://CRAN.R-project.org/package=survival

19. Ahmed KA, Barney BM, Davis BJ, Park SS, Kwon ED, Olivier KR. Stereotactic body radiation therapy in the treatment of oligometastatic prostate cancer. Front Oncol. (2012) 2:215. doi: 10.3389/fonc.2012.00215

20. Ahmed KA, Stauder MC, Miller RC, Bauer HJ, Rose PS, Olivier KR, et al. Stereotactic body radiation therapy in spinal metastases. Int J Radiat Oncol Biol Phys. (2012) 82:e803-9. doi: 10.1016/j.ijrobp.2011.11.036

21. Alongi F, Fogliata A, Clerici E, Navarria P, Tozzi A, Comito T, et al. Volumetric modulated arc therapy with flattening filter free beams for isolated abdominal/pelvic lymph nodes: report of dosimetric and early clinical results in oligometastatic patients. Radiat Oncol. (2012) 7:204. doi: 10.1186/1748-717X-7-204

22. Berkovic P, De Meerleer G, Delrue L, Lambert B, Fonteyne V, Lumen $\mathrm{N}$, et al. Salvage stereotactic body radiotherapy for patients with limited prostate cancer metastases: deferring androgen deprivation therapy. Clin Genitourinary Cancer. (2013) 11:27-32. doi: 10.1016/j.clgc.2012. 08.003

23. Bignardi M, Navarria P, Mancosu P, Cozzi L, Fogliata A, Tozzi A, et al. Clinical outcome of hypofractionated stereotactic radiotherapy for abdominal lymph node metastases. Int J Radiat Oncol Biol Phys. (2011) 81:8318. doi: 10.1016/j.ijrobp.2010.05.032

24. Choi CW, Cho CK, Yoo SY, Kim MS, Yang KM, Yoo HJ, et al. Imageguided stereotactic body radiation therapy in patients with isolated paraaortic lymph node metastases from uterine cervical and corpus cancer. Int J Radiat Oncol Biol Phys. (2009) 74:147-53. doi: 10.1016/j.ijrobp.2008. 07.020

25. Decaestecker K, De Meerleer G, Lambert B, Delrue L, Fonteyne V, Claeys $\mathrm{T}$, et al. Repeated stereotactic body radiotherapy for oligometastatic prostate cancer recurrence. Radiat Oncol. (2014) 9:135. doi: 10.1186/1748-717X-9-135

26. Erler D, Brotherston D, Sahgal A, Cheung P, Loblaw A, Chu W, et al. Local control and fracture risk following stereotactic body radiation therapy for non-spine bone metastases. Radiother Oncol. (2018) 127:3049. doi: 10.1016/j.radonc.2018.03.030

27. Gerszten PC, Burton SA, Ozhasoglu C. CyberKnife radiosurgery for spinal neoplasms. Prog Neurol Surg. (2007) 20:340-58. doi: 10.1159/000100177
28. Guckenberger M, Mantel F, Gerszten PC, Flickinger JC, Sahgal A, Letourneau D, et al. Safety and efficacy of stereotactic body radiotherapy as primary treatment for vertebral metastases: a multi-institutional analysis. Radiat Oncol. (2014) 9:226. doi: 10.1186/s13014-014-0226-2

29. Jereczek-Fossa BA, Piperno G, Ronchi S, Catalano G, Fodor C, Cambria R, et al. Linac-based stereotactic body radiotherapy for oligometastatic patients with single abdominal lymph node recurrent cancer. Am J Clin Oncol. (2014) 37:227-33. doi: 10.1097/COC.0b013e3182610878

30. Kim MS, Cho CK, Yang KM, Lee DH, Moon SM, Shin YJ. Stereotactic body radiotherapy for isolated paraaortic lymph node recurrence from colorectal cancer. World J Gastroenterol. (2009) 15:6091-5. doi: 10.3748/wjg.15.6091

31. Kim MS, Yoo SY, Cho CK, Yoo HJ, Yang KM, Kang JK, et al. Stereotactic body radiotherapy for isolated para-aortic lymph node recurrence after curative resection in gastric cancer. J Korean Med Sci. (2009) 24:48892. doi: $10.3346 / \mathrm{jkms} .2009 .24 .3 .488$

32. Kunos CA, Brindle J, Waggoner S, Zanotti K, Resnick K, Fusco N, et al. Phase II clinical trial of robotic stereotactic body radiosurgery for metastatic gynecologic malignancies. Front Oncol. (2012) 2:181. doi: 10.3389/fonc.2012.00181

33. Nguyen QN, Shiu AS, Rhines LD, Wang H, Allen PK, Wang XS, et al. Management of spinal metastases from renal cell carcinoma using stereotactic body radiotherapy. Int J Radiat Oncol Biol Phys. (2010) 76:118592. doi: 10.1016/j.ijrobp.2009.03.062

34. Owen D, Laack NN, Mayo CS, Garces YI, Park SS, Bauer HJ, et al. Outcomes and toxicities of stereotactic body radiation therapy for non-spine bone oligometastases. Pract Radiat Oncol. (2014) 4:e143e9. doi: 10.1016/j.prro.2013.05.006

35. Wang Z, Wang J, Zhuang H, Wang P, Yuan Z. Stereotactic body radiation therapy induces fast tumor control and symptom relief in patients with iliac lymph node metastasis. Sci Rep. (2016) 6:37987. doi: 10.1038/srep37987

36. Yamada Y, Bilsky MH, Lovelock DM, Venkatraman ES, Toner S, Johnson $\mathrm{J}$, et al. High-dose, single-fraction image-guided intensity-modulated radiotherapy for metastatic spinal lesions. Int J Radiat Oncol Biol Phys. (2008) 71:484-90. doi: 10.1016/j.ijrobp.2007.11.046

37. Yeung R, Hamm J, Liu M, Schellenberg D. Institutional analysis of stereotactic body radiotherapy (SBRT) for oligometastatic lymph node metastases. Radiat Oncol. (2017) 12:105. doi: 10.1186/s13014-0170820-1

38. Gerszten PC, Burton SA, Ozhasoglu C, Welch WC. Radiosurgery for spinal metastases: clinical experience in 500 cases from a single institution. Spine. (2007) 32:193-9. doi: 10.1097/01.brs.0000251863.76595.a2

39. Bishop AJ, Tao R, Rebueno NC, Christensen EN, Allen PK, Wang XA, et al. Outcomes for spine stereotactic body radiation therapy and an analysis of predictors of local recurrence. Int J Radiat Oncol Biol Phys. (2015) 92:101626. doi: 10.1016/j.ijrobp.2015.03.037

40. Hartsell WF, Scott CB, Bruner DW, Scarantino CW, Ivker RA, Roach M III, et al. Randomized trial of short- versus long-course radiotherapy for palliation of painful bone metastases. J Natl Cancer Inst. (2005) 97:798804. doi: 10.1093/jnci/dji139

41. Howell DD, James JL, Hartsell WF, Suntharalingam M, Machtay M, Suh $\mathrm{JH}$, et al. Single-fraction radiotherapy versus multifraction radiotherapy for palliation of painful vertebral bone metastases-equivalent efficacy, less toxicity, more convenient: a subset analysis of Radiation Therapy Oncology Group trial 97-14. Cancer. (2013) 119:888-96. doi: 10.1002/cncr.27616

42. Sprave T, Verma V, Forster R, Schlampp I, Bruckner T, Bostel T, et al. Randomized phase II trial evaluating pain response in patients with spinal metastases following stereotactic body radiotherapy versus threedimensional conformal radiotherapy. Radiother Oncol. (2018) 128:27482. doi: 10.1016/j.radonc.2018.04.030

43. Anand AK, Venkadamanickam G, Punnakal AU, Walia BS, Kumar A, Bansal AK, et al. Hypofractionated stereotactic body radiotherapy in spinal metastasis-with or without epidural extension. Clin Oncol. (2015) 27:34552. doi: 10.1016/j.clon.2015.01.035

44. Jhaveri PM, Teh BS, Paulino AC, Blanco AI, Lo SS, Butler EB, et al. A dose-response relationship for time to bone pain resolution after stereotactic body radiotherapy (SBRT) for renal cell carcinoma (RCC) bony metastases. Acta Oncol. (2012) 51:584-8. doi: 10.3109/0284186X.2011. 652741 
45. Nguyen QN, Chun SG, Chow E, Komaki R, Liao Z, Zacharia R, et al. Singlefraction stereotactic vs. conventional multifraction radiotherapy for pain relief in patients with predominantly nonspine bone metastases: a randomized phase 2 trial. JAMA Oncol. (2019). doi: 10.1001/jamaoncol.2019.0192. [Epub ahead of print].

46. Muldermans JL, Romak LB, Kwon ED, Park SS, Olivier KR. Stereotactic body radiation therapy for oligometastatic prostate cancer. Int J Radiat Oncol Biol Phys. (2016) 95:696-702. doi: 10.1016/j.ijrobp.2016.01.032

47. Farooqi A, Bishop AJ, Narang S, Allen PK, Li J, McAleer MF, et al. Outcomes after hypofractionated dose-escalation using a simultaneous integrated boost technique for treatment of spine metastases not amenable to stereotactic radiosurgery. Pract Radiat Oncol. (2019) 9:e142-e8. doi: 10.1016/j.prro.2018.10.008
Conflict of Interest Statement: The authors declare that the research was conducted in the absence of any commercial or financial relationships that could be construed as a potential conflict of interest.

The handling editor declared a past co-authorship with the authors JS and MM.

Copyright (c) 2019 Jacobs, Palta, Williamson, Price, Czito, Salama and Moravan. This is an open-access article distributed under the terms of the Creative Commons Attribution License (CC BY). The use, distribution or reproduction in other forums is permitted, provided the original author(s) and the copyright owner(s) are credited and that the original publication in this journal is cited, in accordance with accepted academic practice. No use, distribution or reproduction is permitted which does not comply with these terms. 